\title{
LA-UR-21-27787
}

Approved for public release; distribution is unlimited.

Title:

Today on Mars

Author(s):

Wiens, Roger Craig

Robinson, Scott Henry

Intended for: News from Mars Screen on Central Park Square

Issued:

2021-08-04 
Disclaimer:

Los Alamos National Laboratory, an affirmative action/equal opportunity employer, is operated by Triad National Security, LLC for the National Nuclear Security Administration of U.S. Department of Energy under contract 89233218CNA000001. By approving this article, the publisher recognizes that the U.S. Government retains nonexclusive, royalty-free license to publish or reproduce the published form of this contribution, or to allow others to do so, for U.S. Government purposes. Los Alamos National Laboratory requests that the publisher identify this article as work performed under the auspices of the U.S. Department of Energy. Los Alamos National Laboratory strongly supports academic freedom and a researcher's right to publish; as an institution, however, the Laboratory does not endorse the viewpoint of a publication or guarantee its technical correctness. 


\section{Today On Mars}

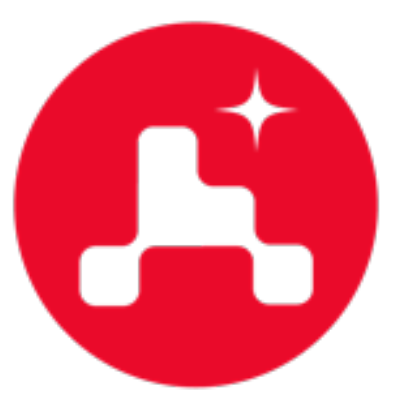

MARS ट020 PERSEVERANCE
Pictures and Information on the NASA Perseverance Rover, its onboard instruments and the Ingenuity Helicopter

(2) LOS Alamos 


\section{Mars 2020/Perseverance}

Over the past two decades, missions flown Wars Exploration Program have 列 discovered by landed and orbital missidence to wet conditions billions of years ago. The point environments lasted long enough to potentiall support the development of microbiallife.

The Mars 2020/Perseverance rover is designed to better understand the geology of Mars and seek signs of ancient life. The mission will collect and store a set of rock and soil samples that could be returned to Earth in the future. It will also test new

technology to benefit future robotic and human

Key Objectives

- Explore a geologically diverse landing site

- Assess ancient habitability

- Seek signs of ancient life, particularly in special rocks known to preserve signs of life over time

- Gather rock and soil samples that could be Gather rock and soil samples that could be
returned to Earth by a future NASA mission

- Demonstrate technology for future robotic and human exploration



g
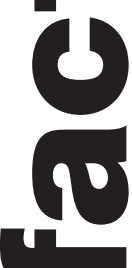

$<$
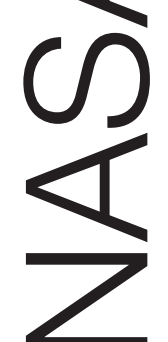

Mission Timeline

- Launch July 30, 2020 from Cape Canaveral Air Force Station, Florida

- Land on Mars on February 18, 2021 at the site of an ancient river delta in a lake that once filled Jezero Crater

- Spend at least one Mars year (two Earth years) exploring the landing site region 


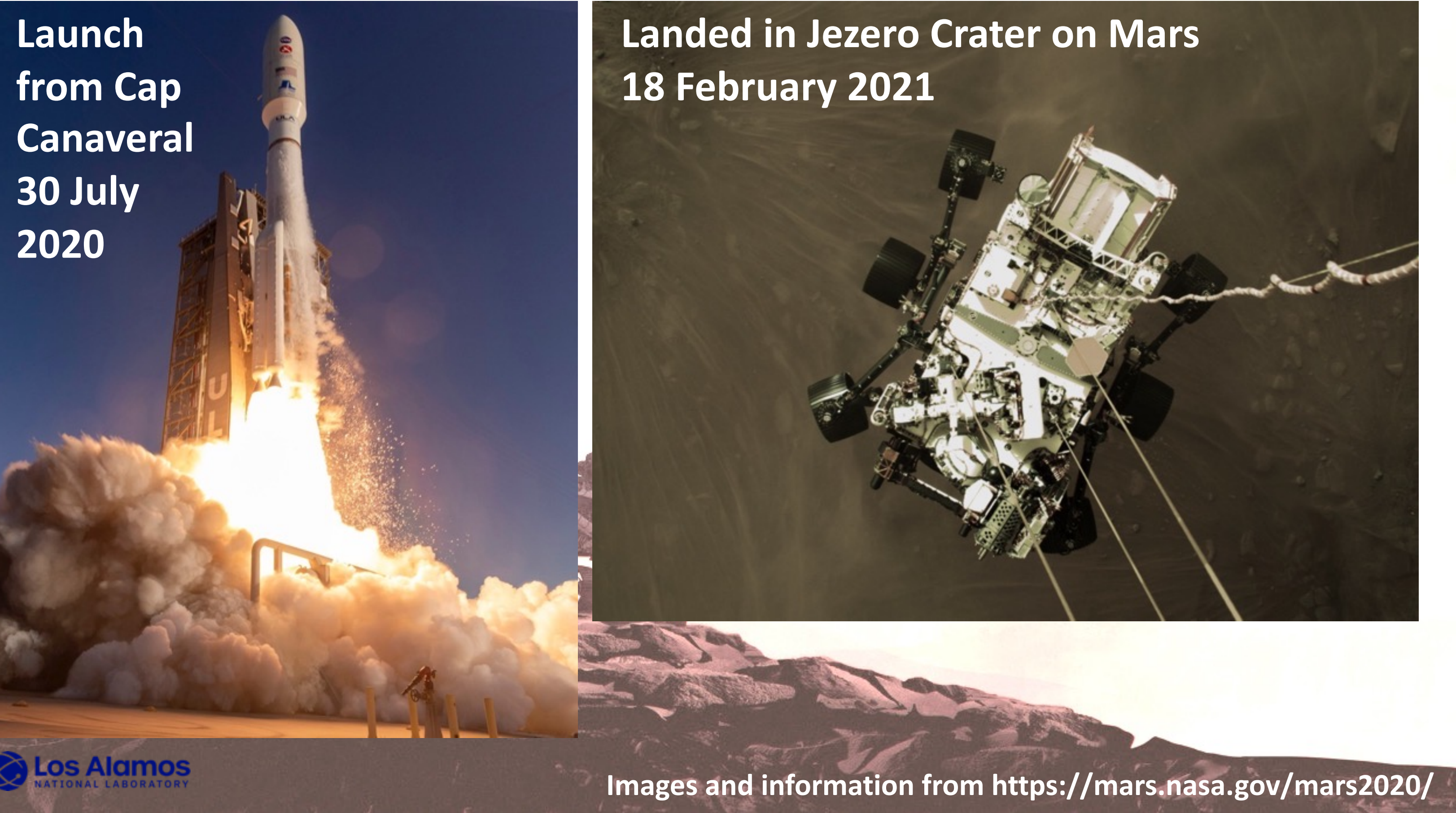





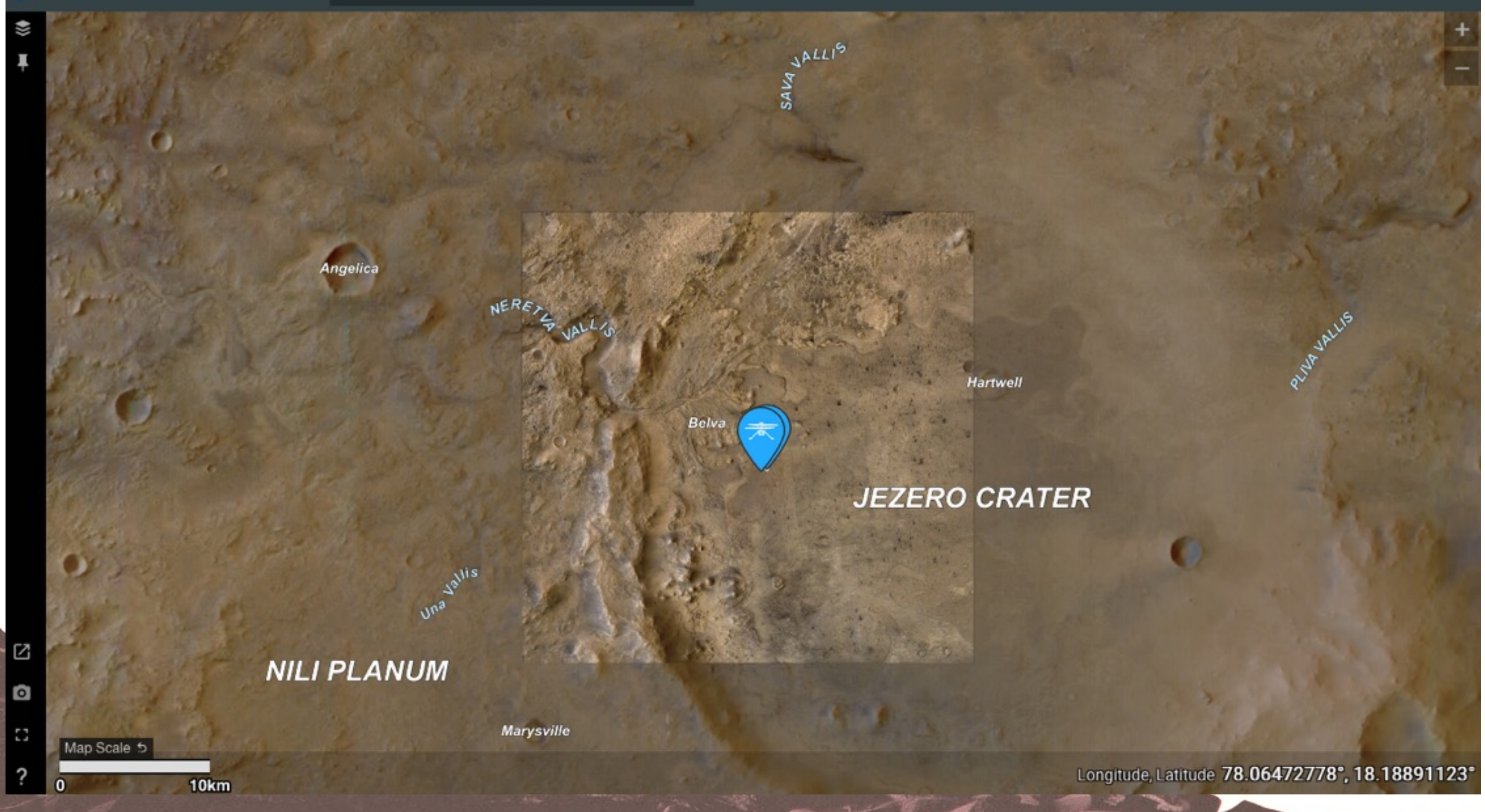




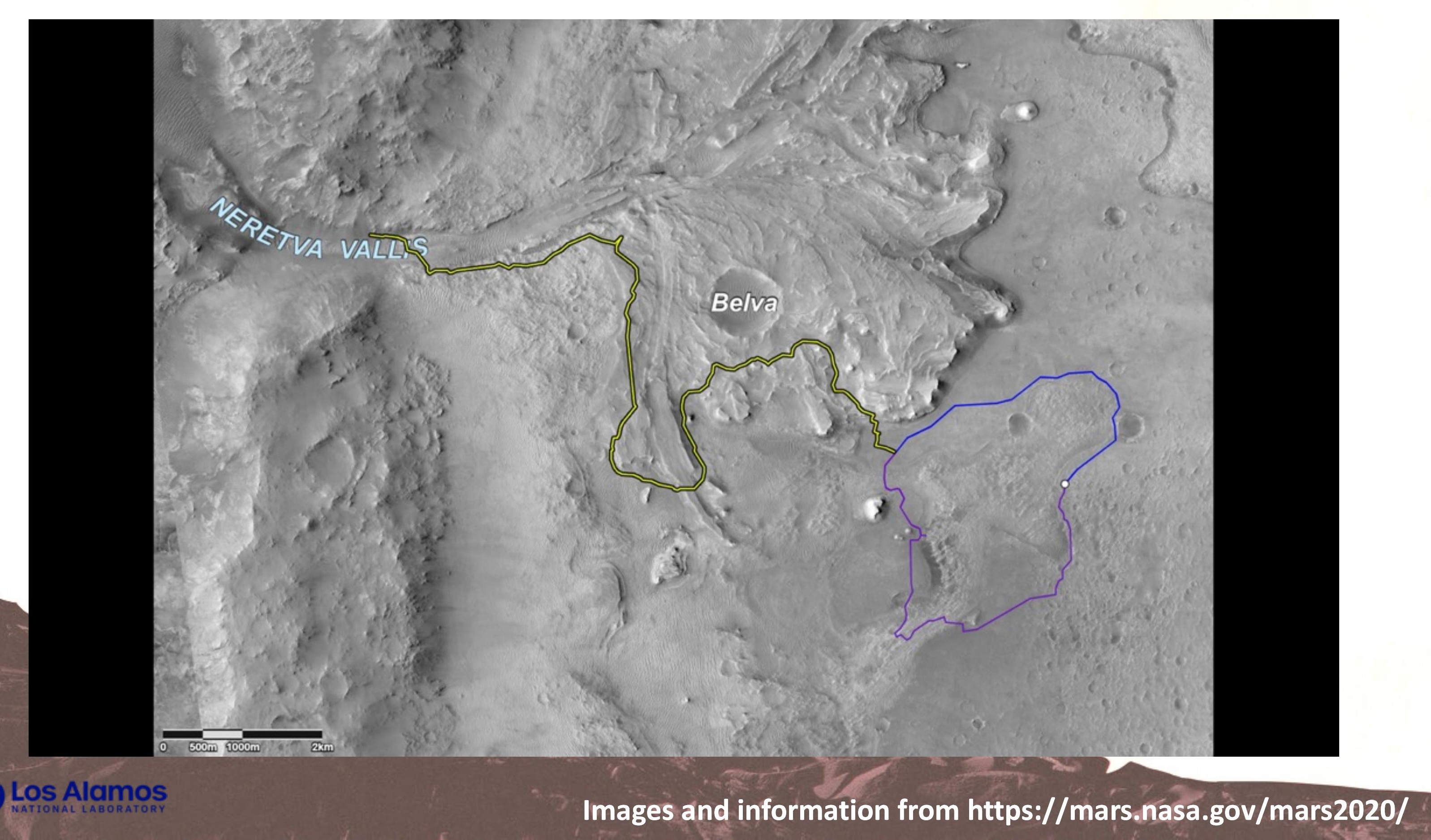




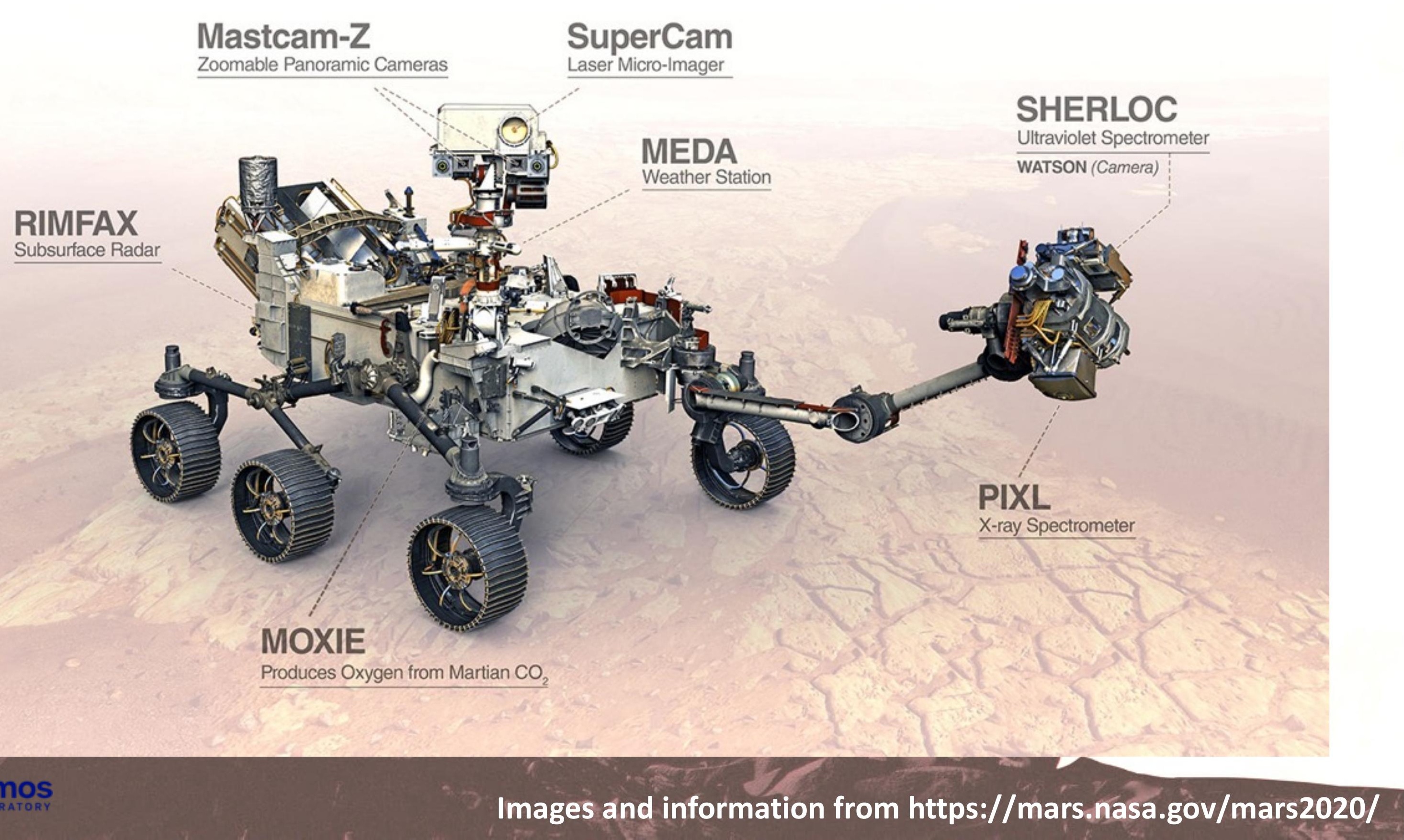









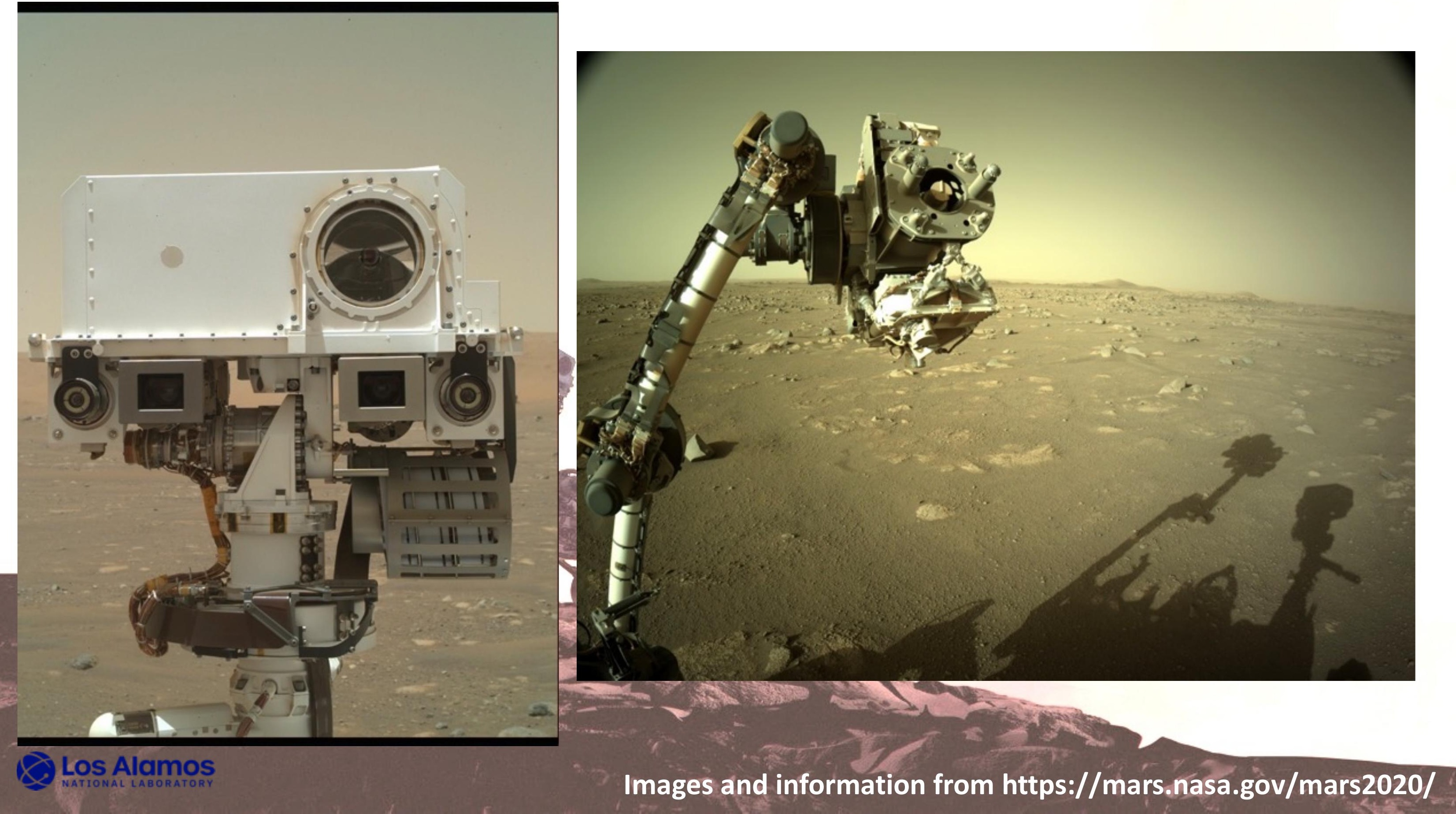




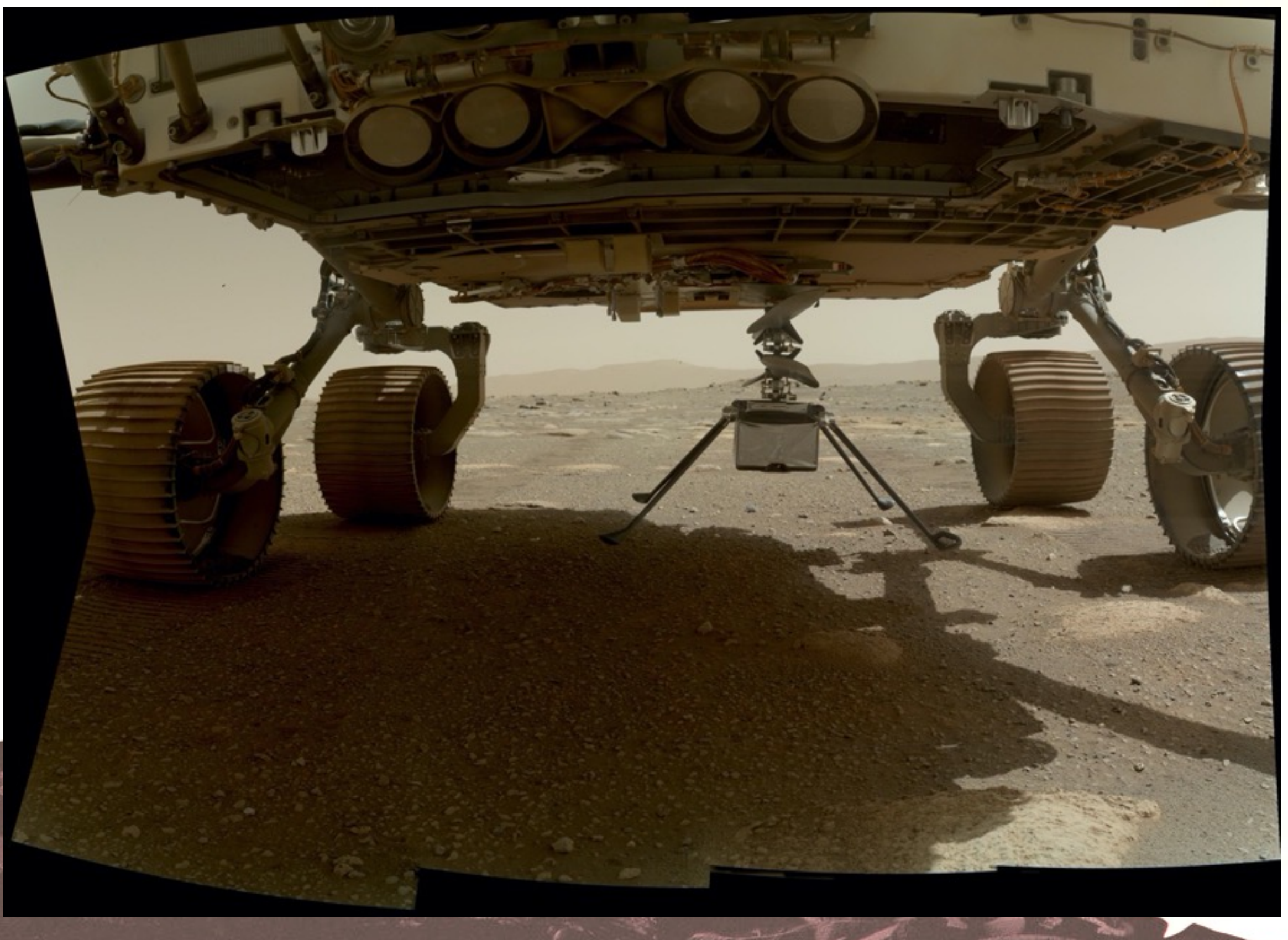




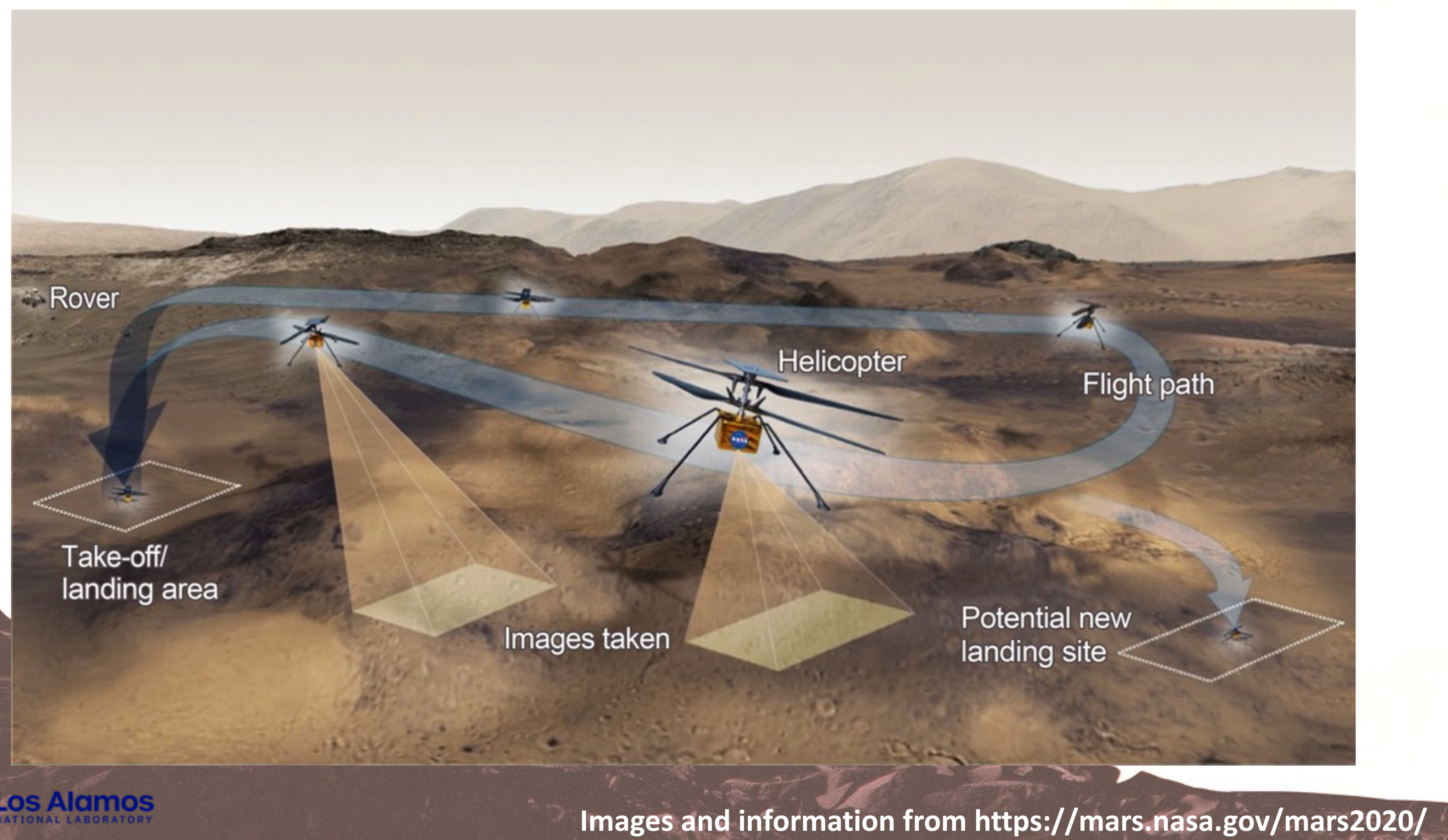




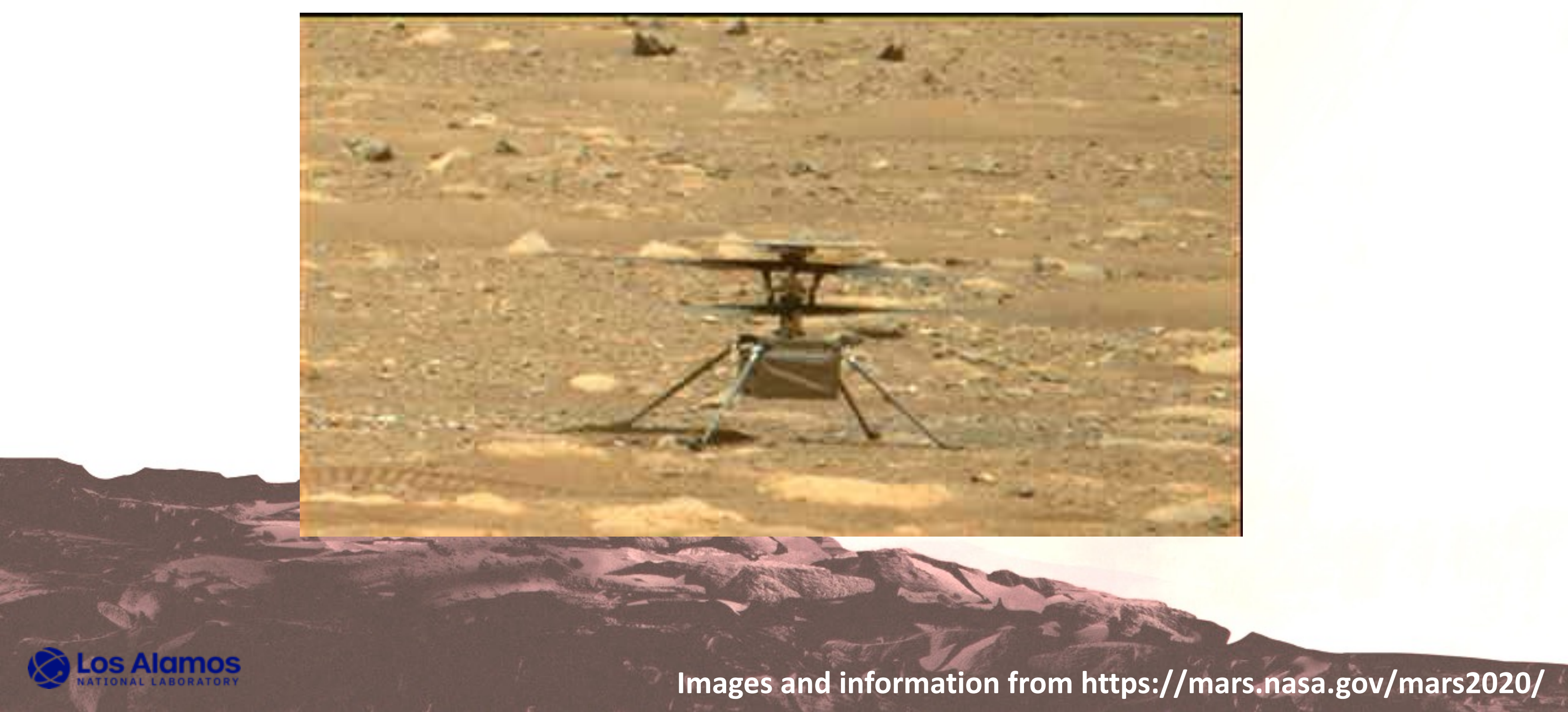




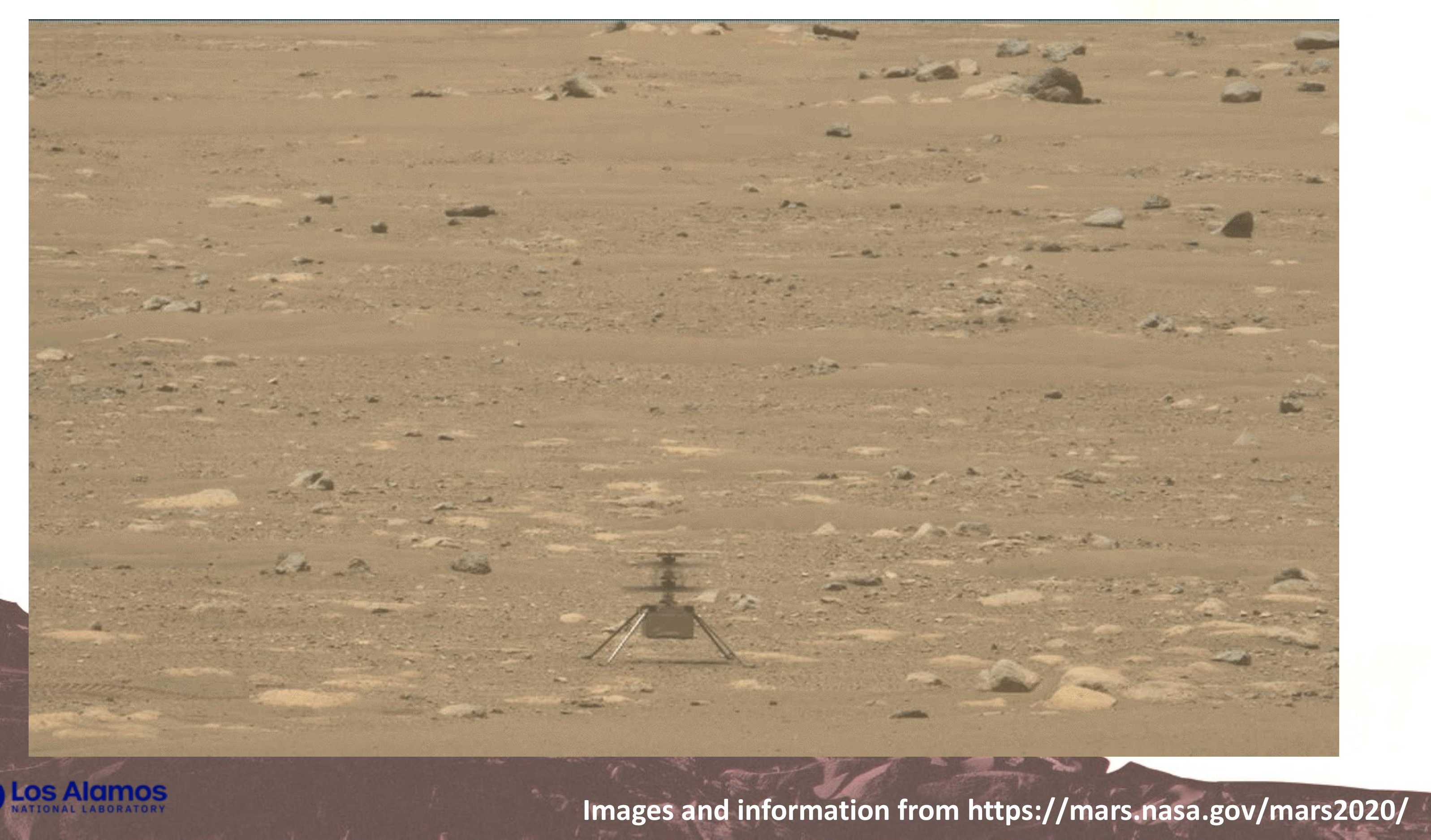




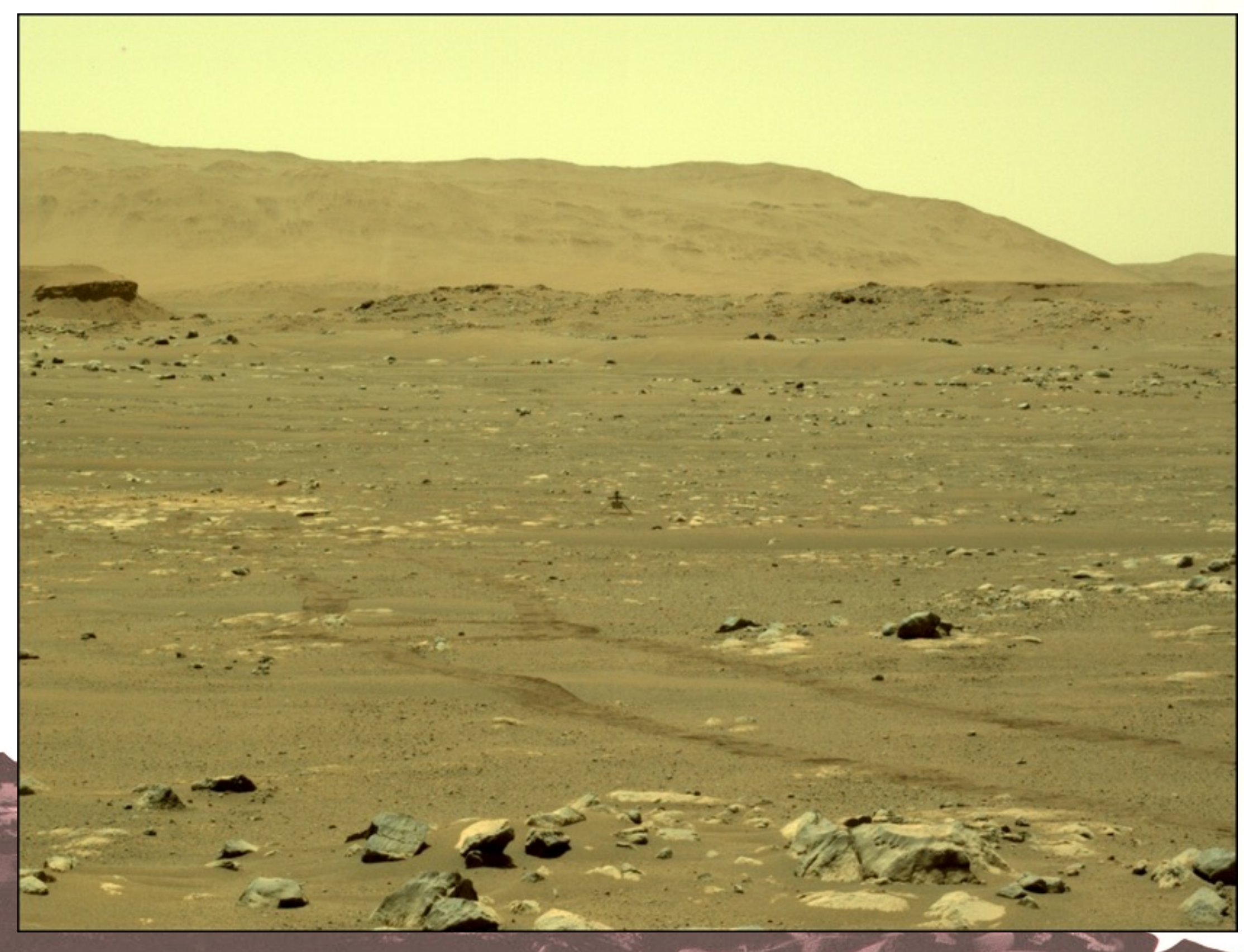






$$
x
$$




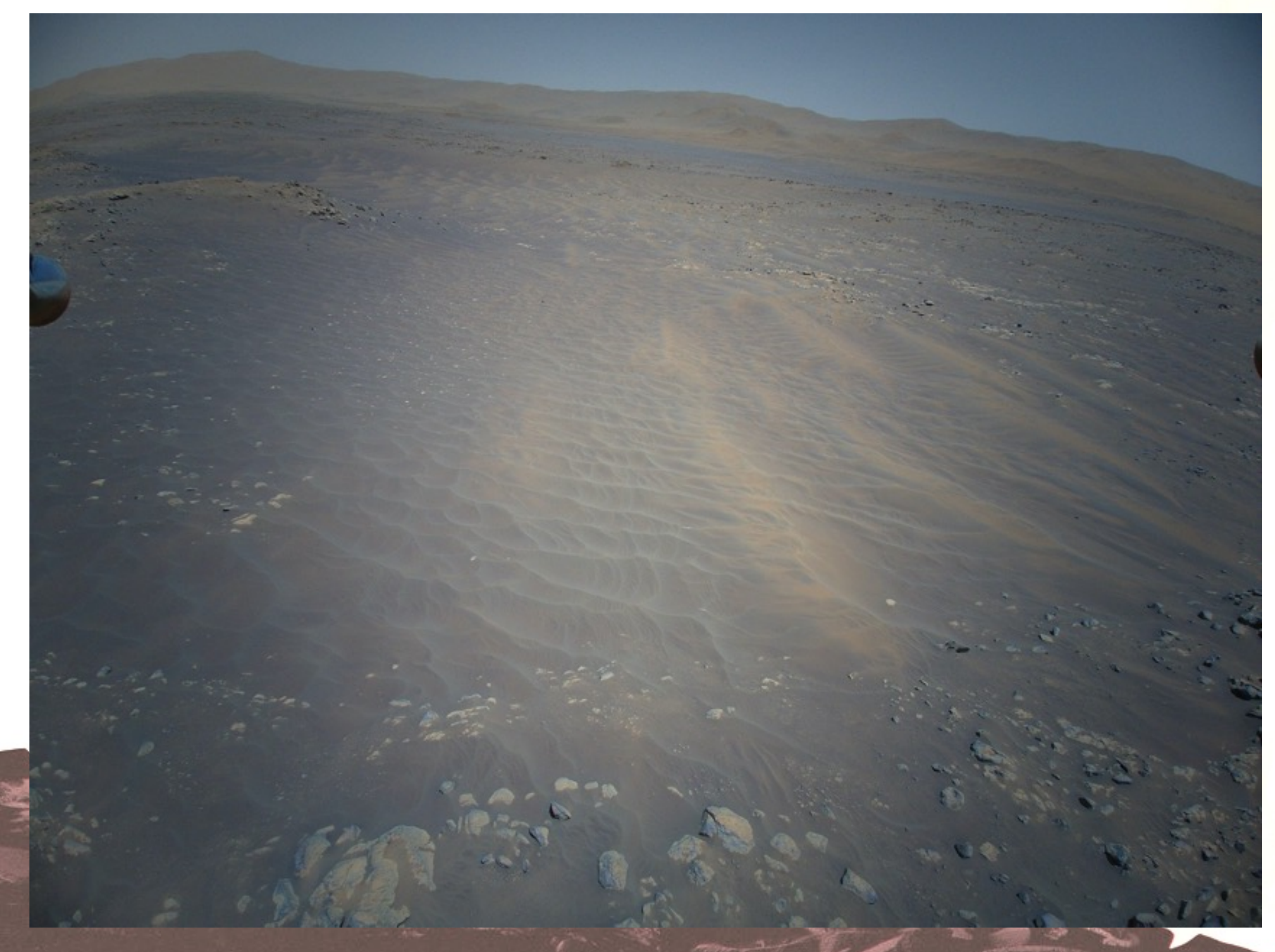




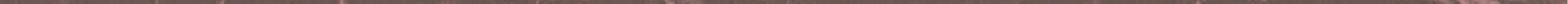




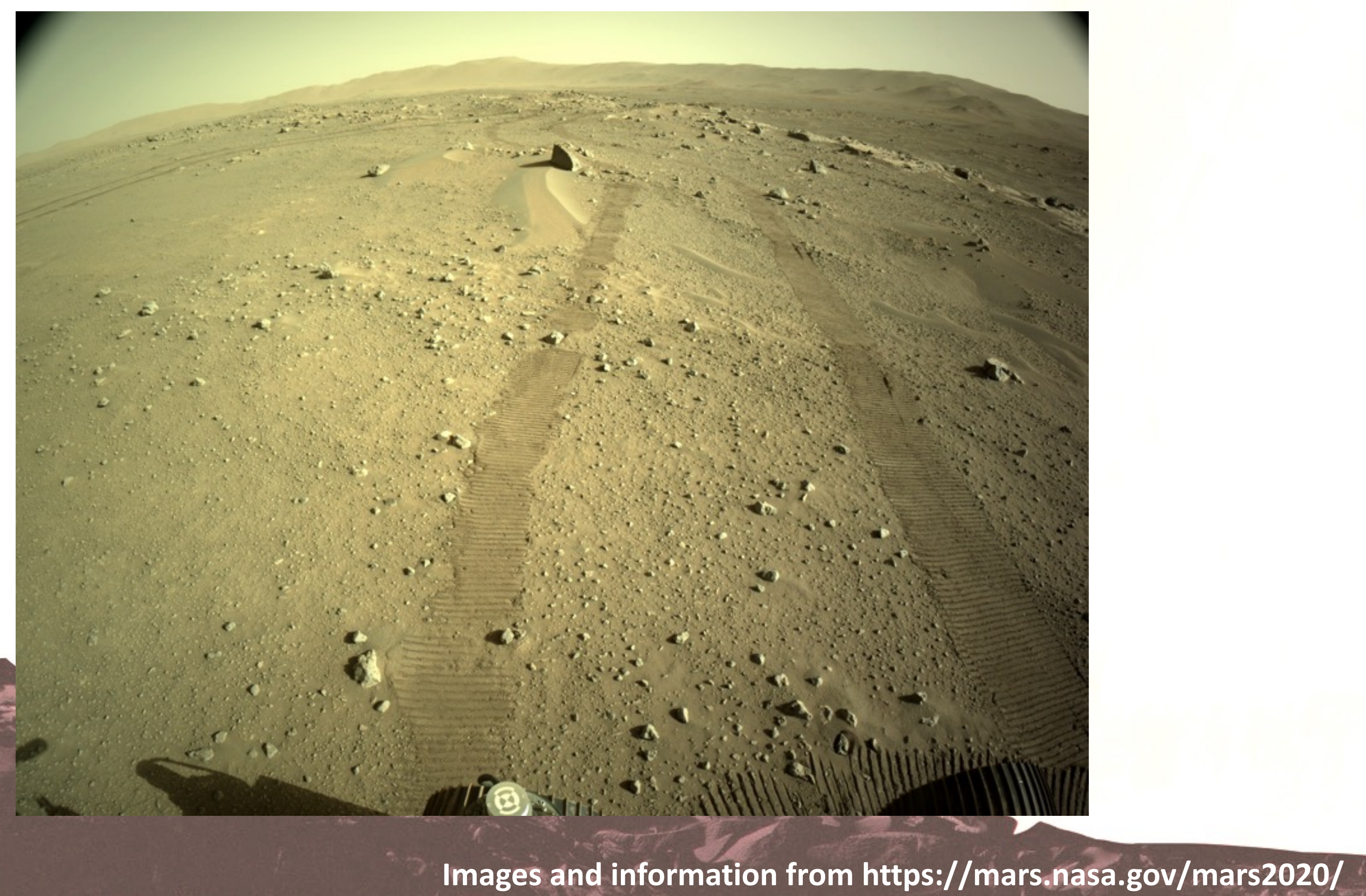





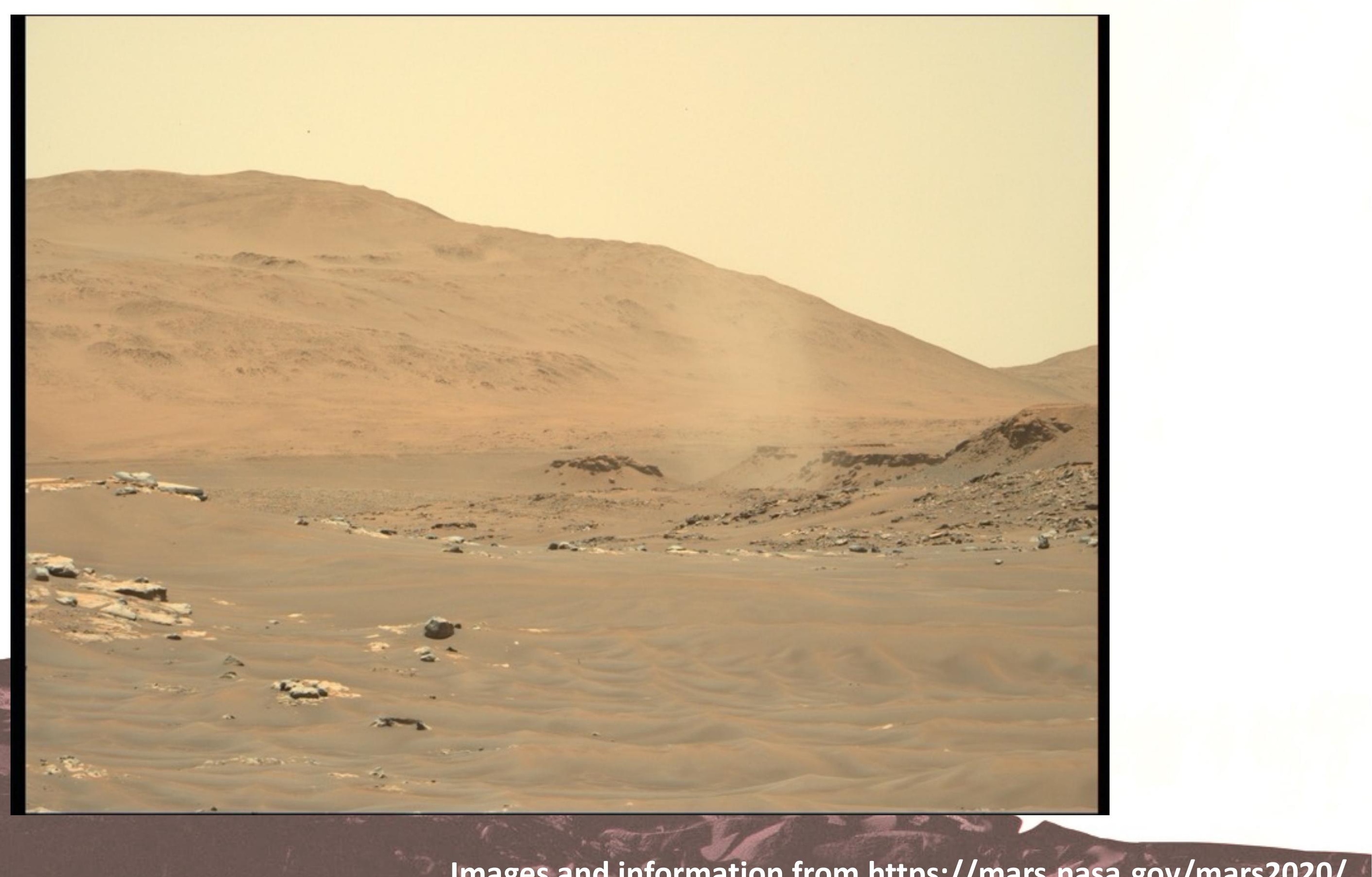

Images and information from https://mars.nasa.gov/mars2020/ 





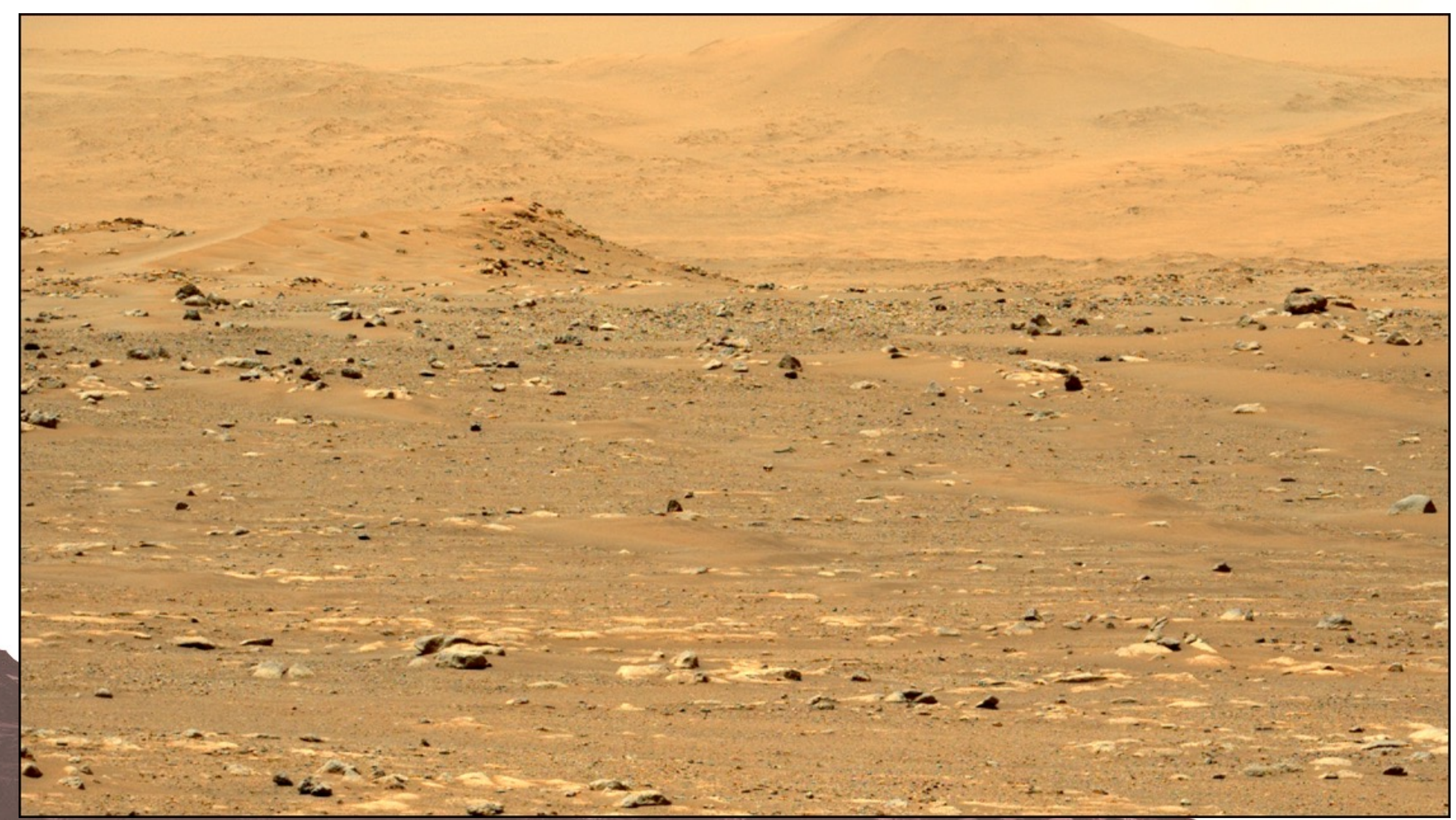




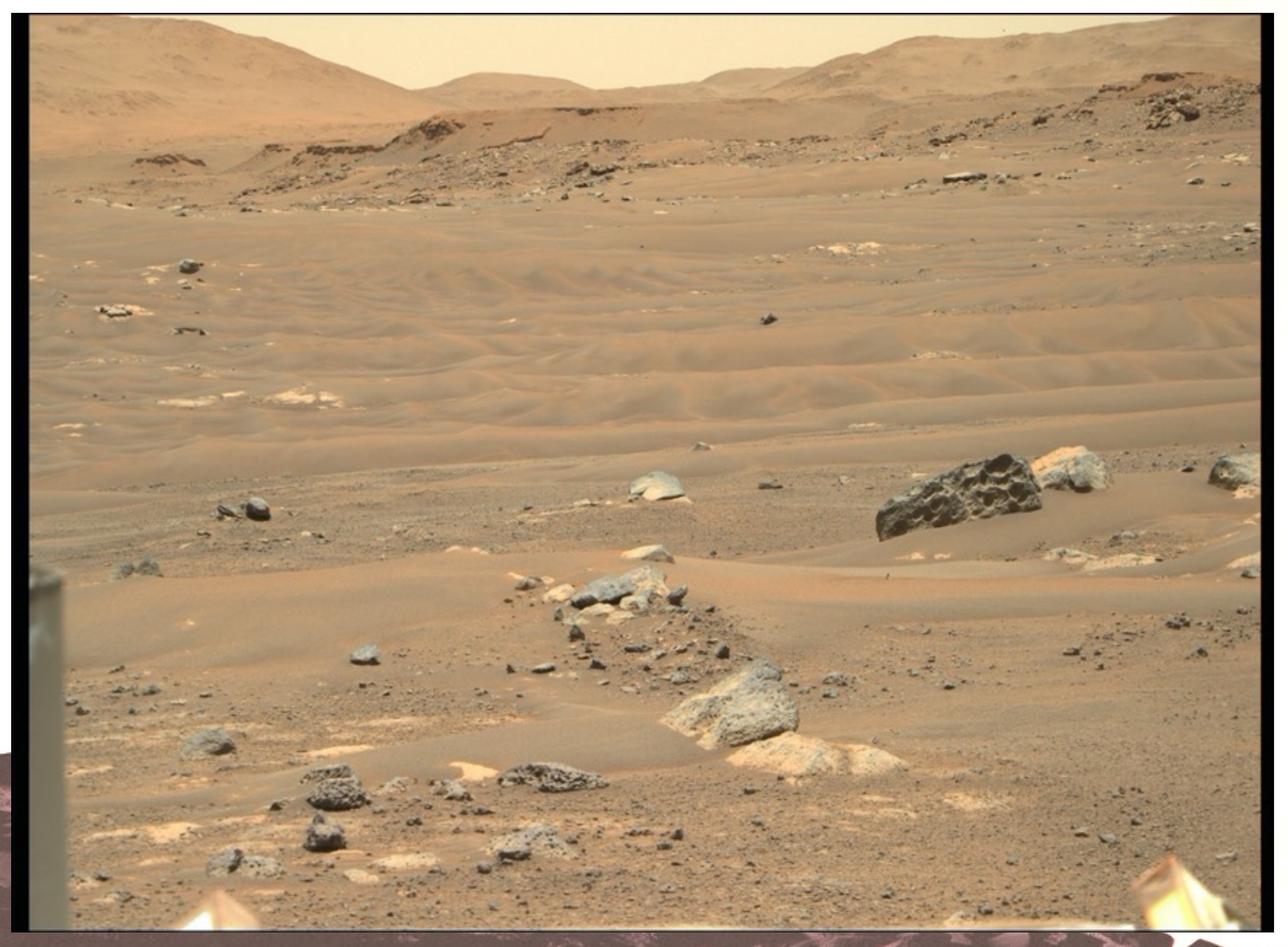








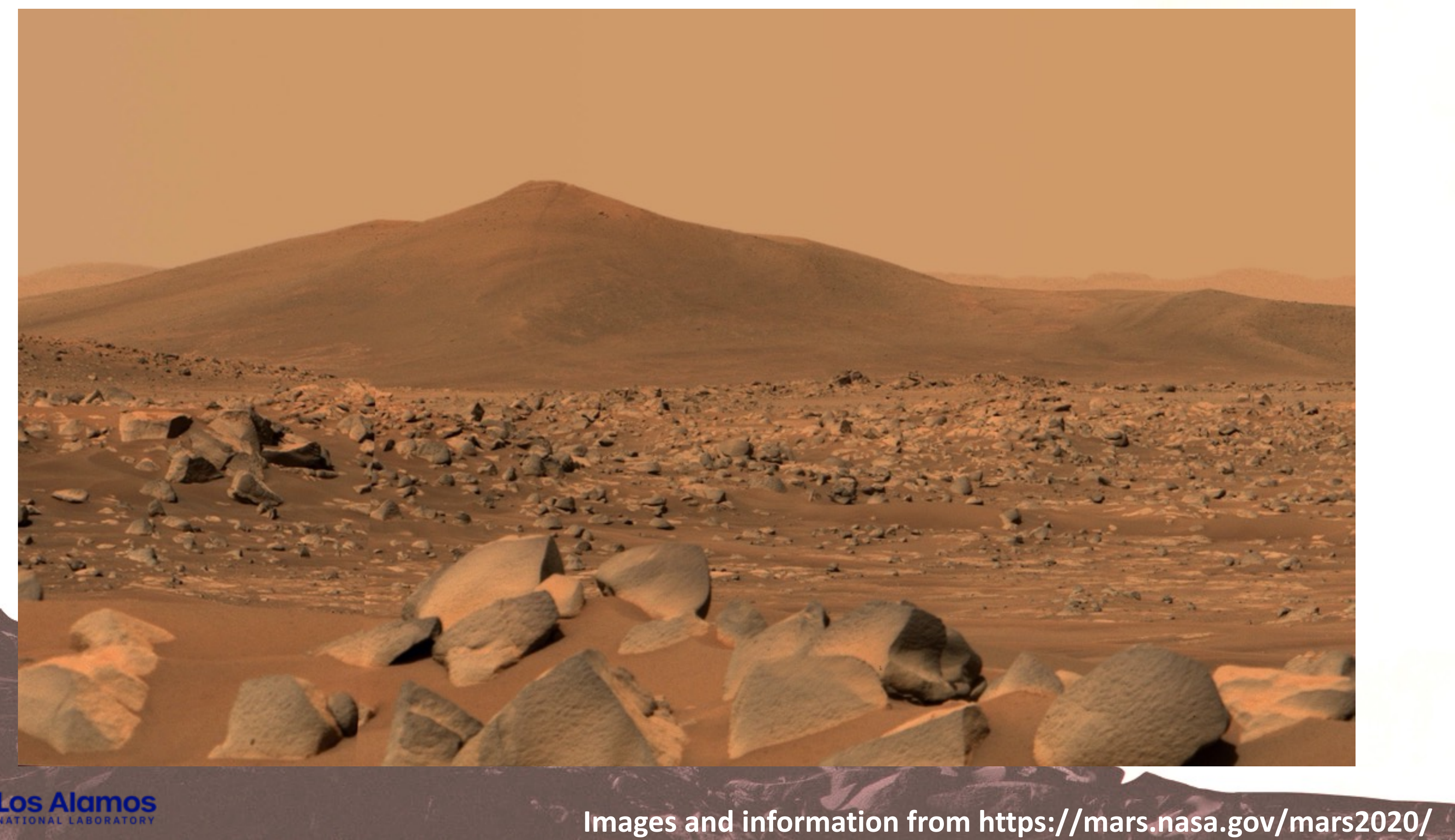




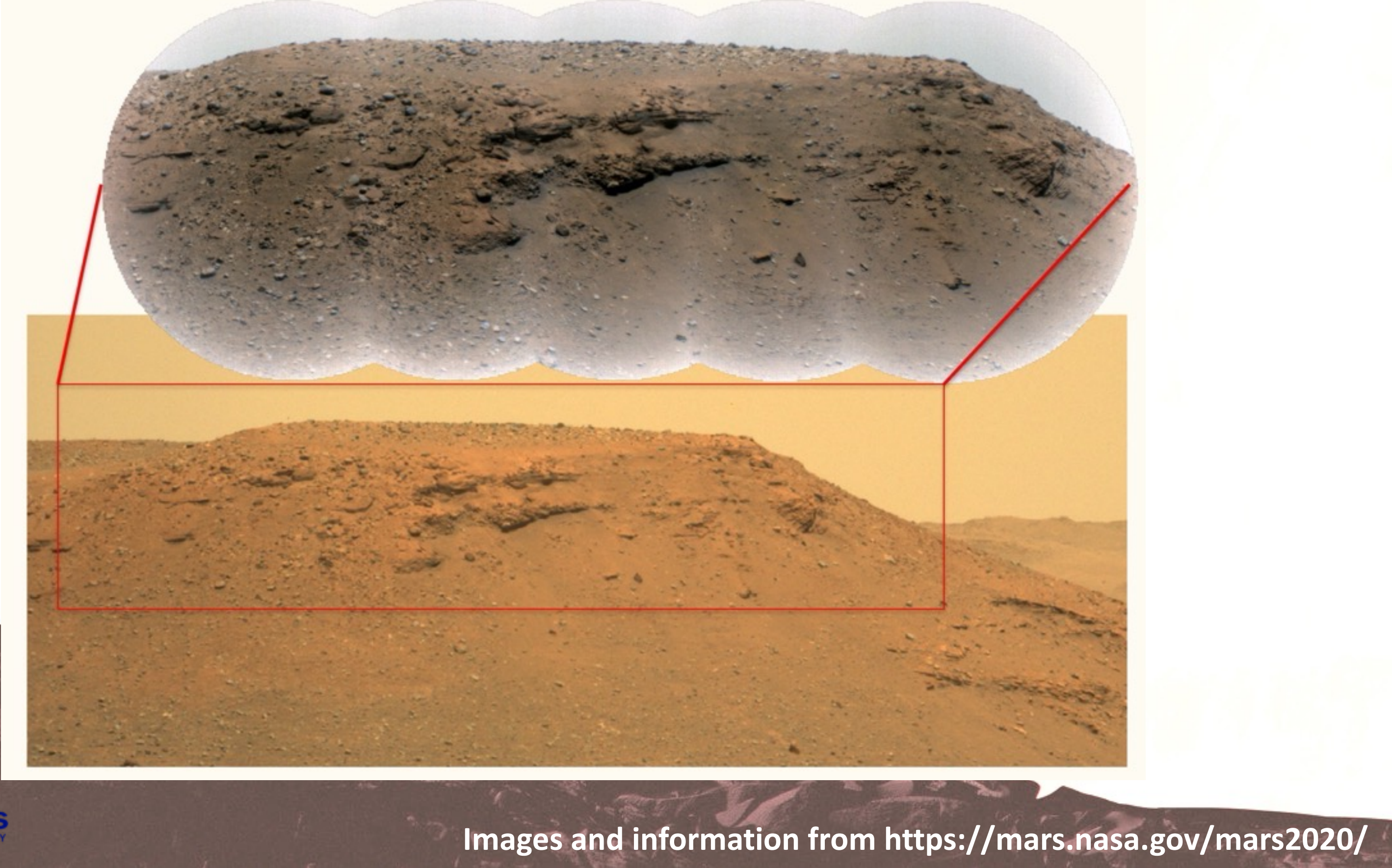


First Target: Máaz (Sol 12)

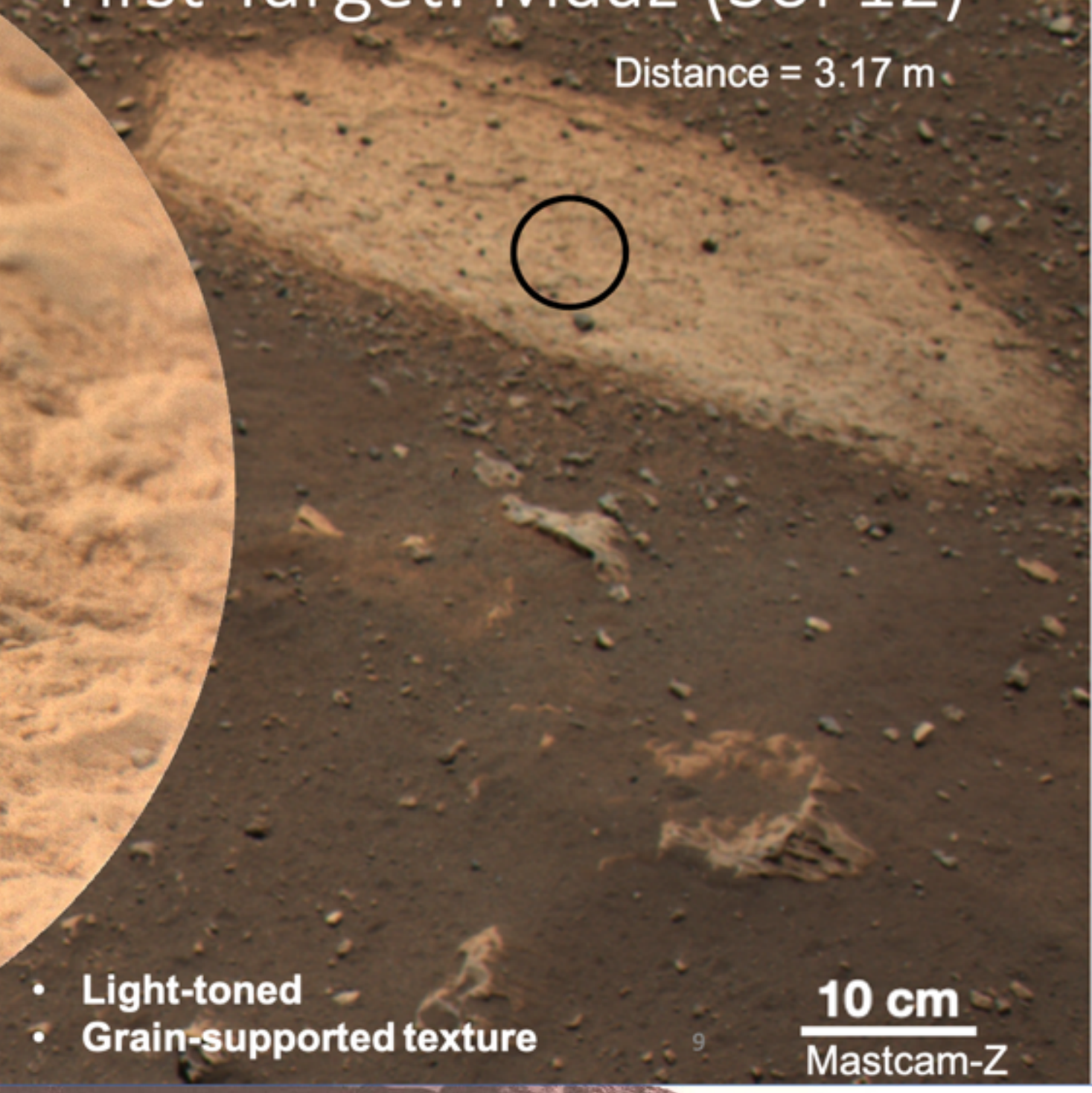

SuperCam

Remote

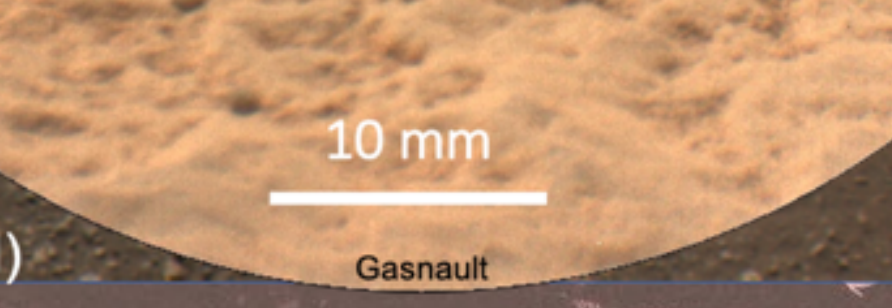

Micro-Imager (RMI)

- Grain-supported texture

Mastcam-Z 


\section{Maaz target (Sol 12)}

\section{$1^{\text {st }}$ SuperCam LIBS spectrum}

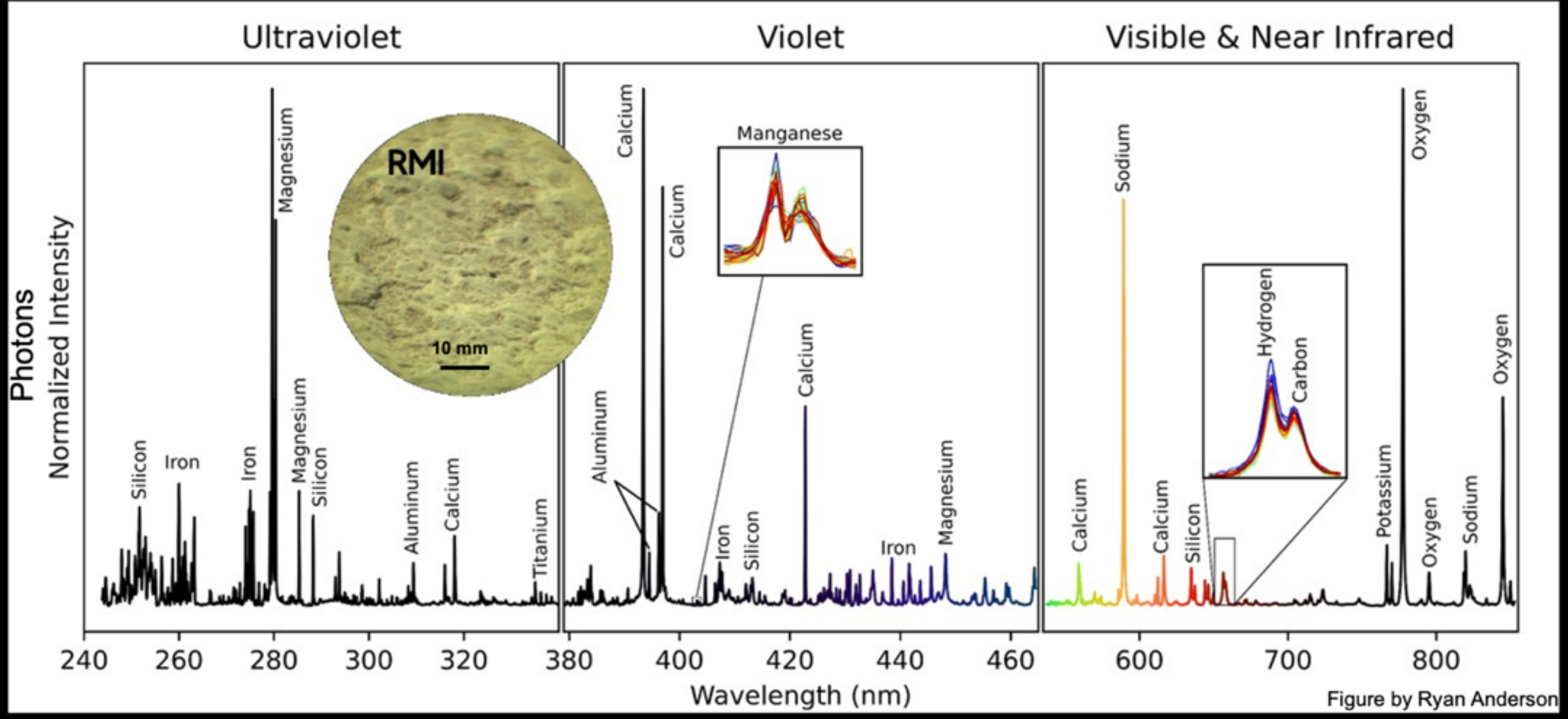




\section{Martian acoustics}

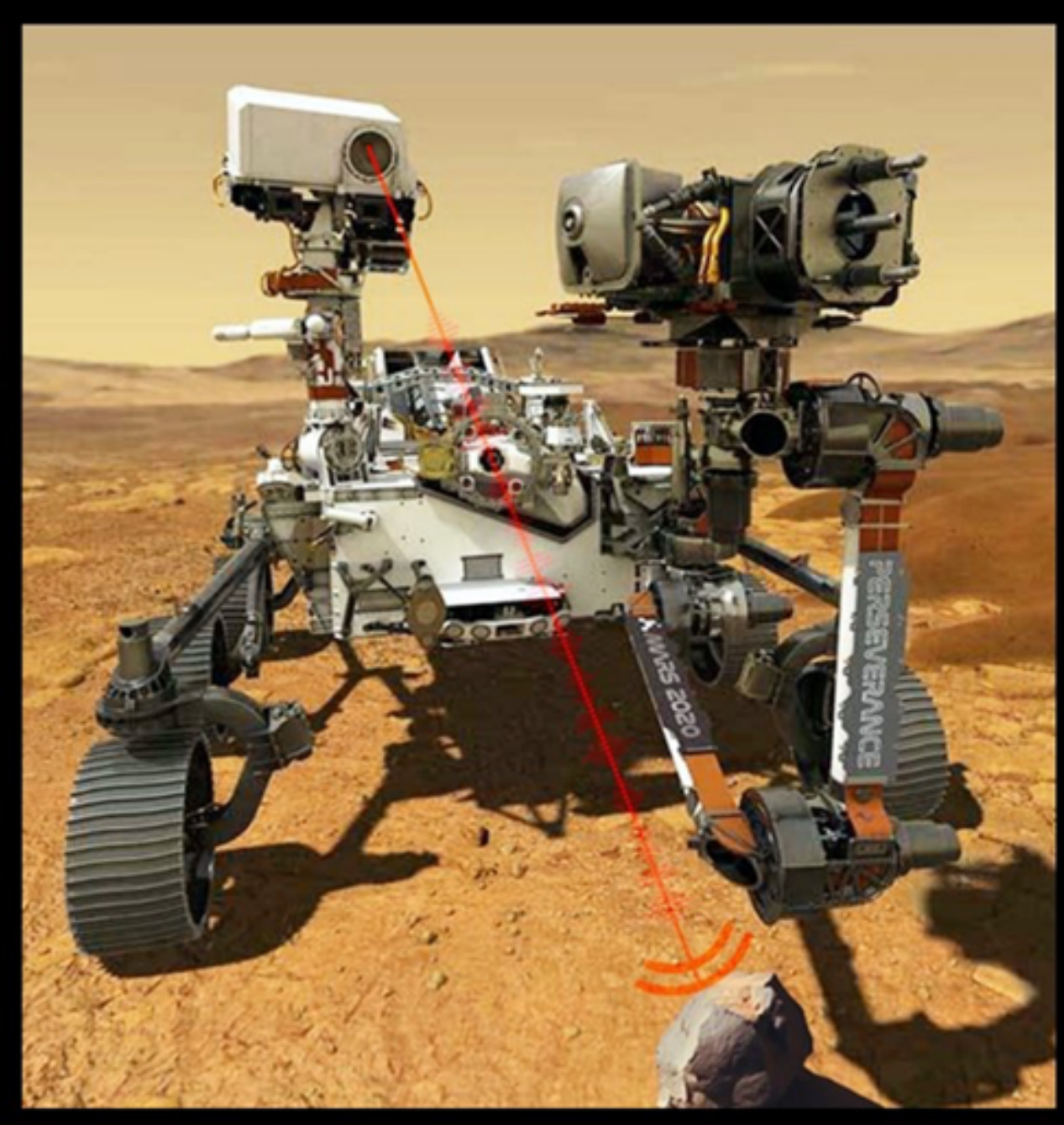

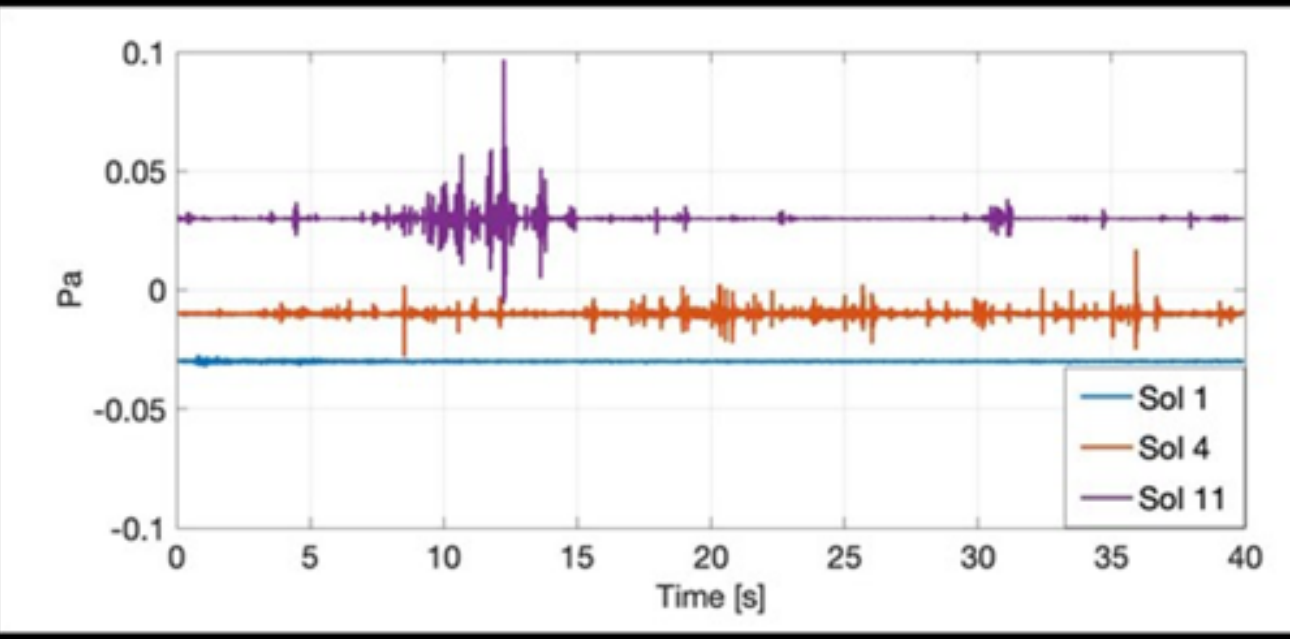

Sol 1: First recording of sounds on Mars Sol 4: First acoustic recording of the wind Sol 12: First recording of laser shots

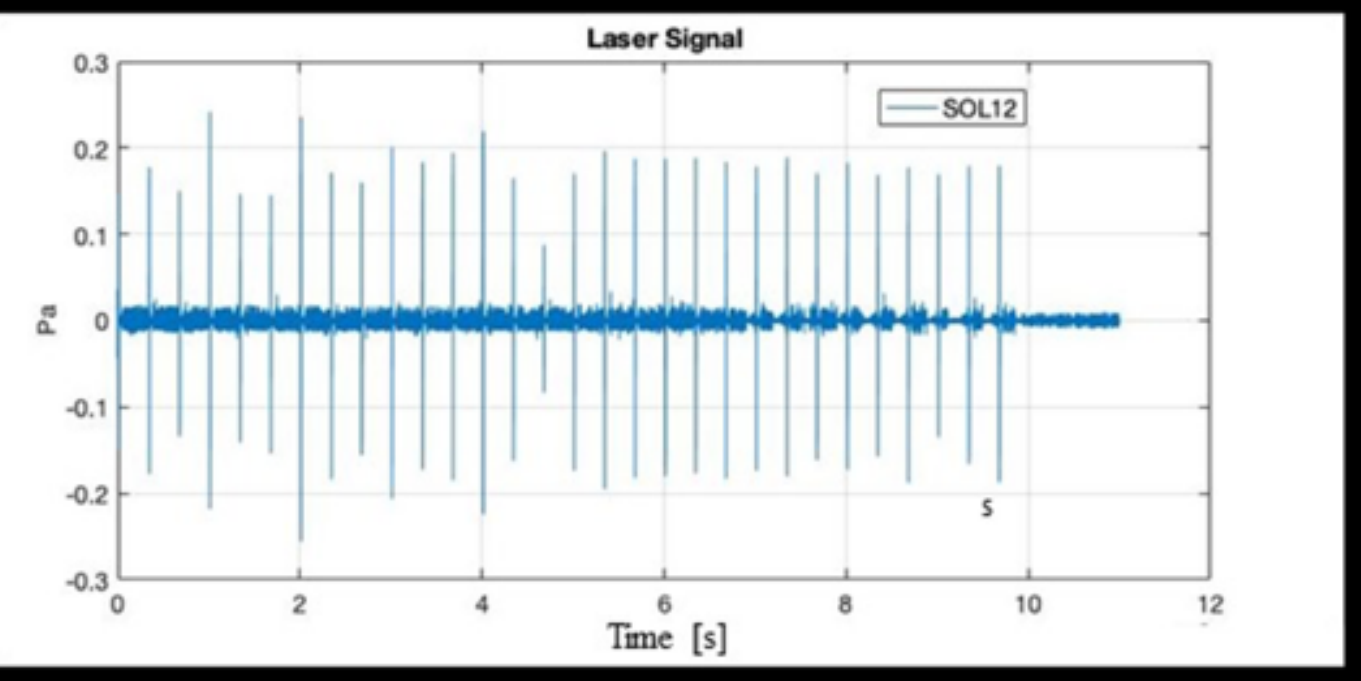




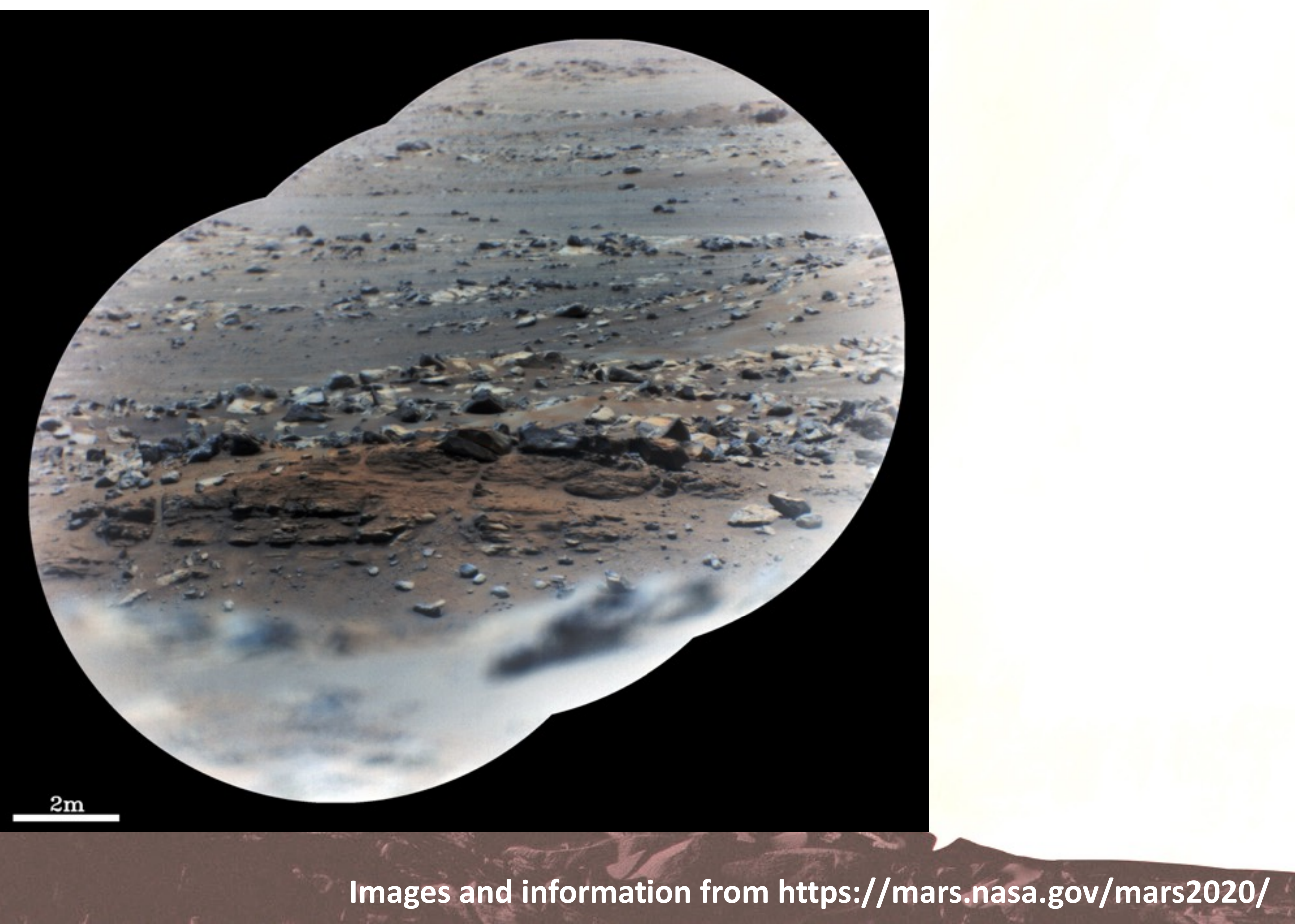






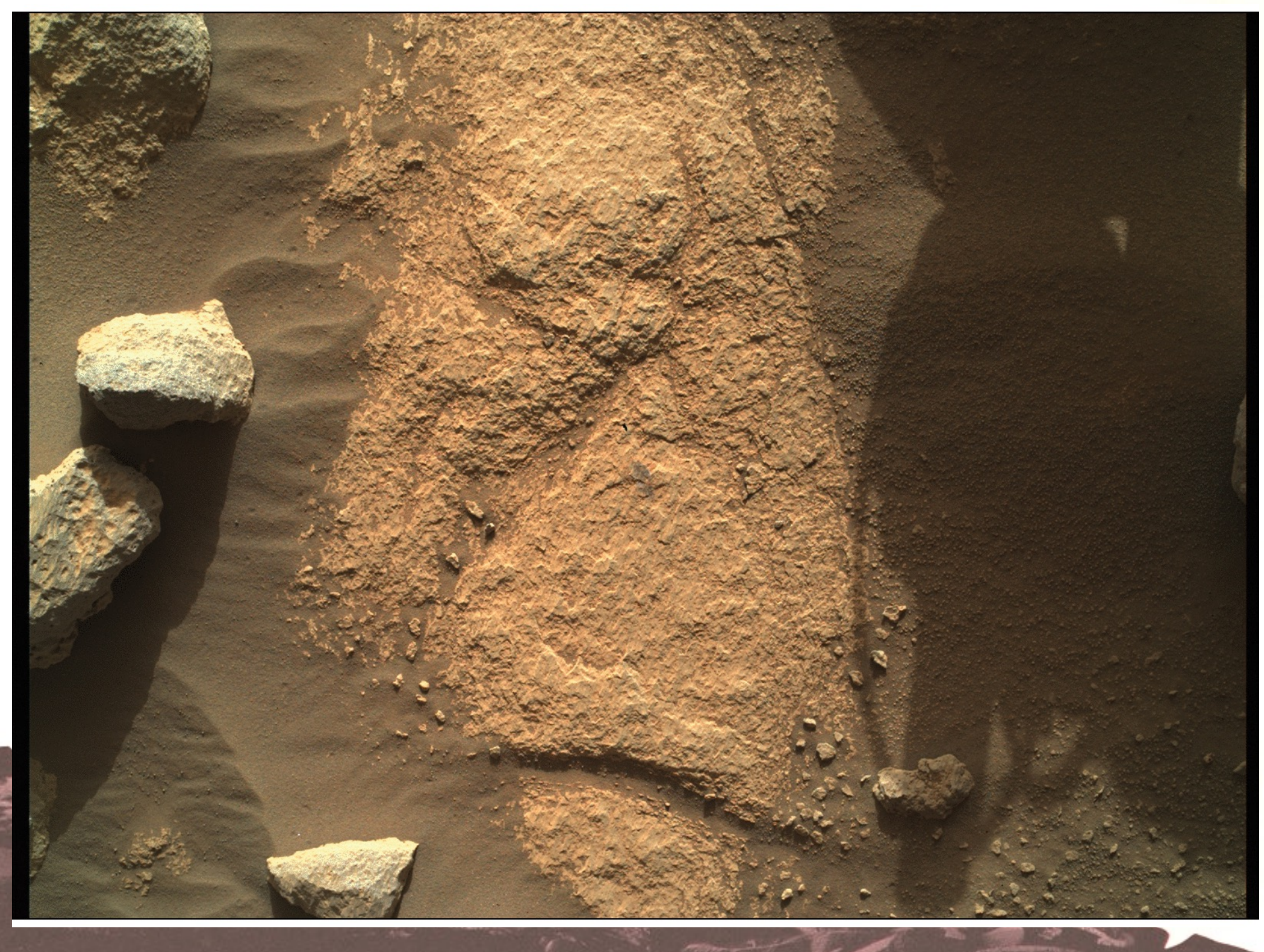

Images and information from https://mars.nasa.gov/mars2020/ 


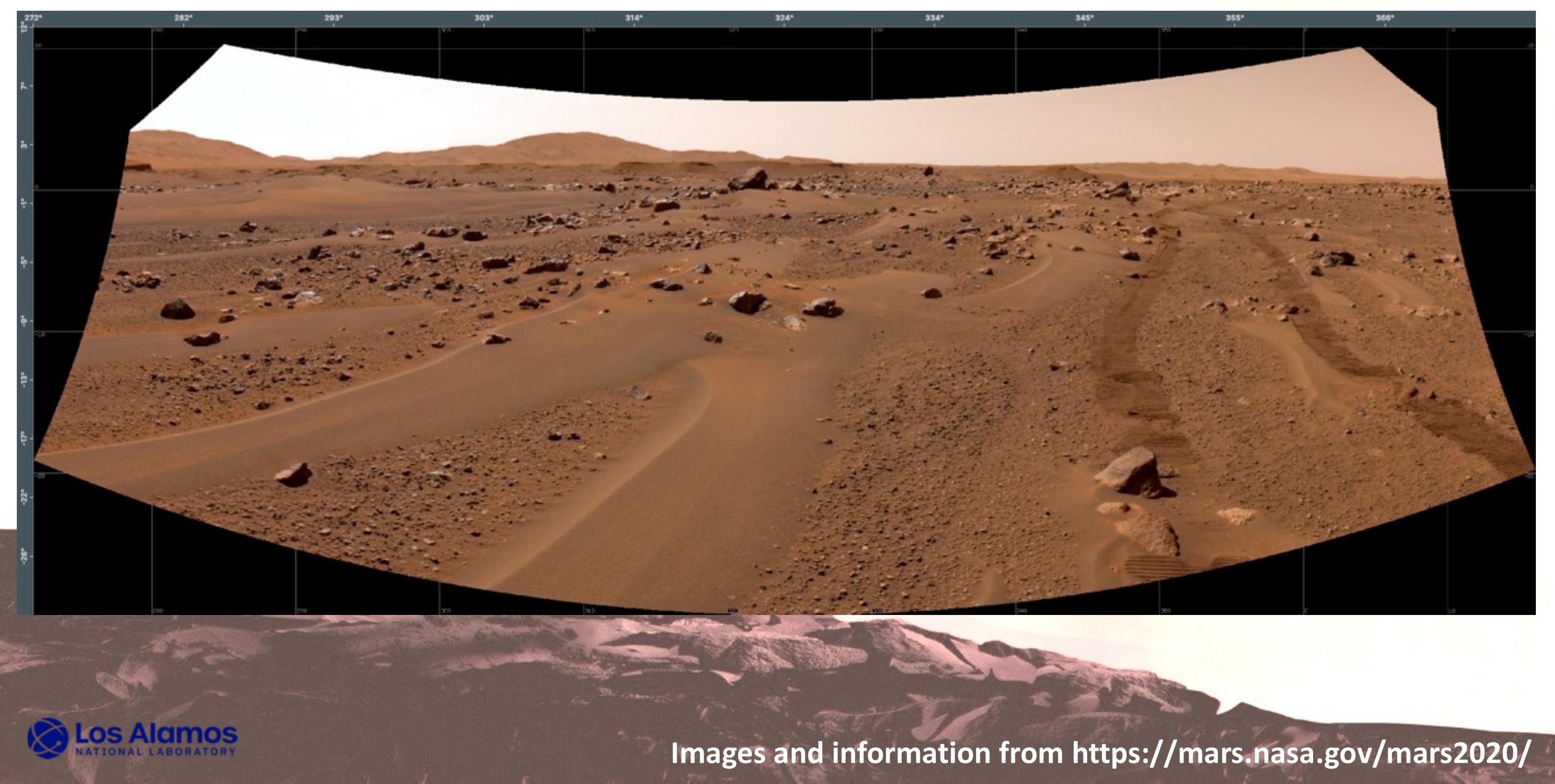




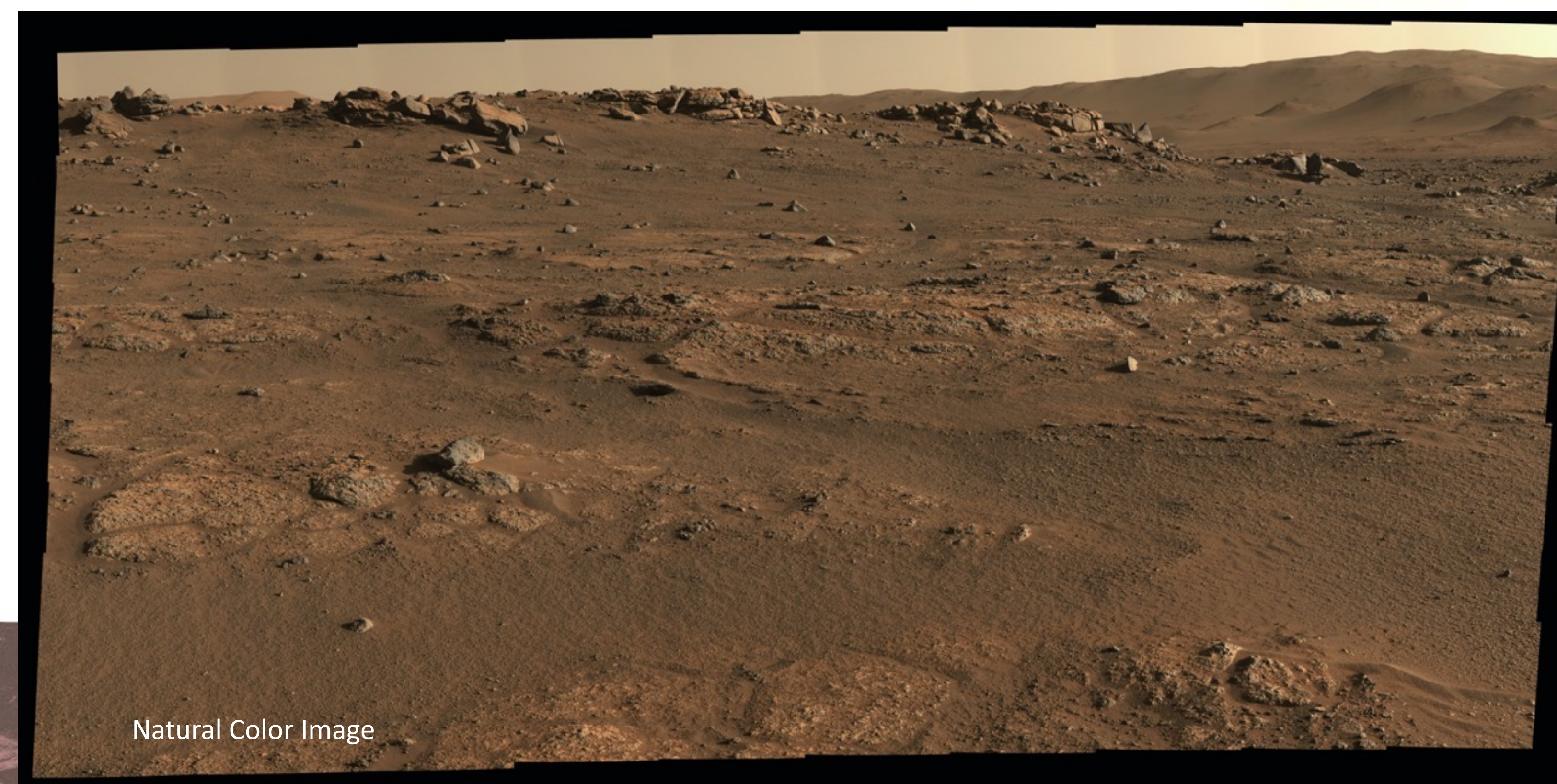

Natural Color Image 


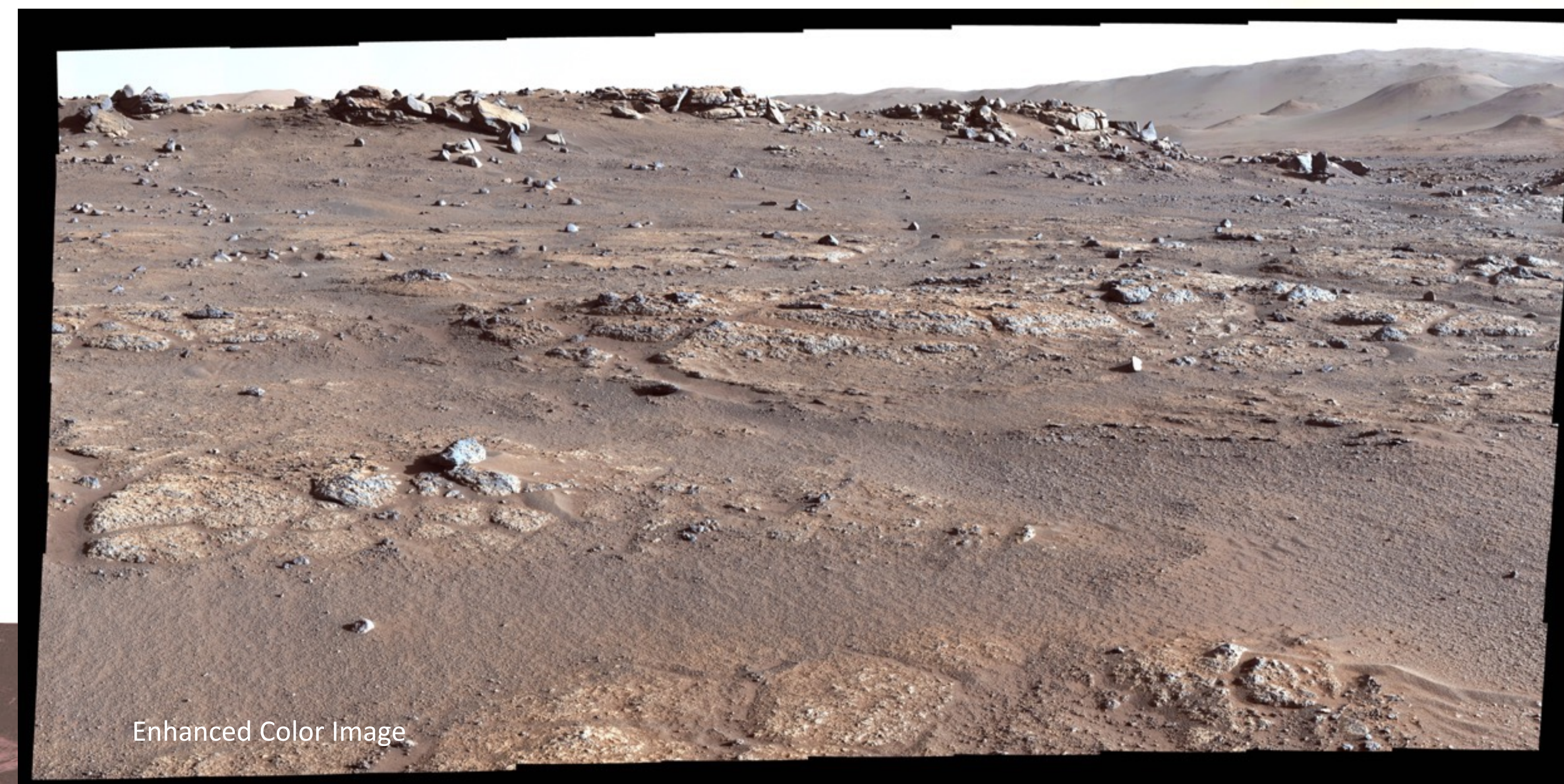

